\title{
GAMBARAN KONSEP DIRI MAHASISWA DITINJAU DARI PERSPEKTIF BUDAYA
}

\author{
Alifah Nabilah Masturah \\ Fakultas Psikologi, Universitas Muhammadiyah Malang \\ alifah_nabilah@umm.ac.id
}

\begin{abstract}
Pearson use cultural values to descride theirselves. Therefore, important for the individual to see how others judges them for self-assessment. This study aims to determine the image of student self-concept with cultural background. This research uses descriptive quantitative approach. Accidental sampling method is used in determining the subject of research. The subjects of the study were students of Psychology Faculty University of Muhammadiyah Malang, amounting to 261 people from different backgrounds. The instrument used in this study is an open question developed by the researcher based on theoretical understanding of self concept. The data analysis used in this research is cross tabulation. The results show that subjects describe themselves in 4 groups, namely: according to self, father, mother, and friend. Each group describes itself as an interdependent and independent self. Fathers, mothers and friends tended to assess the subject's self-concept in the interdependent category. While the subject rate of self concept tend to be in independent category. Other results showed the four self-conceptual selfassessment groups. However, demographic variables, such as sex, age, ethnicity, and origin of the archipelago have no relevance to self-concept, except self-concept assessments by mother and tribal demographics with weak associations.
\end{abstract}

Keywords: Culture, Self-Concept, student

Abstrak. Individu menggunakan nilai budaya sebagai acuan dalam menggambarkan diri. Sehingga penting bagi individu untuk melihat bagaimana pandangan orang lain untuk menilai diri sendiri. Penelitian ini bertujuan untuk mengetahui gambaran konsep diri mahasiswa dengan latar belakang budayanya. Penelitian ini menggunakan pendekatan kuantitatif deskriptif. Metode accidental sampling digunakan dalam menentukan subjek penelitian. Subjek penelitian adalah mahasiswa Fakultas Psikologi Universitas Muhammadiyah Malang yang berjumlah 261 orang dari berbagai latar belakang yang berbeda. Instrumen yang digunakan dalam penelitian ini berupa pertanyaan terbuka yang dikembangkan sendiri oleh peneliti berdasarkan pada pemahaman teoritis konsep diri. Analisis data yang digunakan dalam penelitian ini adalah tabulasi silang. Hasil menunjukkan bahwa subjek menggambarkan diri mereka kedalam 4 kelompok, yaitu: menurut diri sendiri, ayah, ibu, dan teman. Setiap kelompok menggambarkan diri interdependen dan diri independen. Ayah, ibu dan teman cenderung menilai konsep diri subjek dalam kategori interdependen. Sedangkan subjek menilai konsep dirinya cenderung pada kategori independen. Hasil lainnya menunjukkan keempat kelompok penilaian konsep diri saling terkait. Akan tetapi, variabel demografi, seperti jenis kelamin, usia, suku, dan asal kepulauan tidak memiliki keterkaitan dengan konsep diri, kecuali penilaian konsep diri menurut ibu dan demografi suku yang memiliki keterkaitan yang lemah.

Kata kunci: Budaya, Konsep diri, mahasiswa

\section{PENDAHULUAN}

Budaya merupakan semua hal

yang diterima seseorang dari komunitasnya (Lowie, 1917). Nilai-nilai yang diinternalisasi oleh individu kedalam diri mereka termasuk didalamnya. Penelitian yang dilakukan sebelumnya menunjukkan perbedaan konsep diri yang dimiliki seseorang dengan latar belakang budaya yang berbeda (Watkins \& Andres, 
1997; Eaton \& Louw, 2000; Tarakanita \& Widiarti, 2002; Yaman \& Mesman, 2010; Fuadhy \& Retnowati, 2013). Budaya berperan signifikan terhadap pembentukan diri dan identitas.

Secara umum, dunia membagi dua kategori komunitas berdasarkan orientasi nilai budayanya, yakni individualis dan kolektivis (Hofstede, 1980). Negara barat memiliki konsep individualis yang berfokus pada kemandirian, sedangkan negara timur memiliki konsep kolektivis dengan arti saling bergantung/terikat (Markus \& Kitayama, 1991). Indonesia termasuk negara dibagian timur dengan budaya kolektivis. Kelompok kolektivis menggambarkan diri mereka berdasarkan konteks sosial mereka (Markus \& Kitayama, 1991). Dibandingkan dengan kelompok individualis, orang-orang dalam kelompok kolektivis memiliki perhatian lebih dalam terhadap nilai-nilai didalam keluarga mereka sebagai komponen yang membentuk konsep dirinya (Fuadhy \& Retnowati, 2013).

Individu tumbuh dan berkembang dengan nilai budaya. Ketika seseorang mulai tumbuh, maka diri mereka juga akan berkembang. Pada saat itu, tekanan dalam aktualisasi beralih dari fisiologis menjadi psikologis. Bentuk dan fungsi tubuh berkembang mencapai tingkat perkembangan dewasa, dan pertumbuhan berpusat pada kepribadian (Schultz, 1991). Kepribadian individu dewasa merupakan cerminan dari pemahaman yang mereka dapatkan tentang diri mereka sendiri, yang disebut oleh Rogers sebagai konsep diri. Konsep diri terbentuk dari masa kanak-kanak hingga akhir masa remaja (Schultz, 1991). Sehingga, mahasiswa yang umumnya berada pada rentang usia 18-22 tahun berada pada usia perkembangan remaja akhir (Santrock, 2010). Berdasarkan pemahaman tersebut, diketahui bahwa budaya berperan dalam membentuk konsep diri seseorang. Sehingga, penelitian ini akan melihat gambaran konsep diri mahasiswa dengan latar belakang budayanya.

Rogers mendefinisikan konsep diri sebagai bentuk persepsi mengenai diri sendiri yang terorganisir. Konsep diri berkembang melalui identifikasi figur lekat dalam keluarga dan sekolah (Burns, 1993). Konsep diri menurut Fuhrmann (1990) merupakan konsep dasar tentang diri sendiri, pikiran dan opini pribadi, kesadaran tentang apa dan siapa dirinya, dan bagaimana perbandingan antara dirinya dengan orang lain serta bagaimana idealisme yang telah dikembangkannya. Sejalan dengan itu, Brooks (dalam Rakhmat, 2008) menjelaskan konsep diri sebagai persepsi terhadap diri individu sendiri, baik yang bersifat fisik, sosial dan psikologis yang diperoleh melalui pengalaman dari interaksi individu dengan orang lain. Sedangkan Afif (2015) menjelaskan konsep diri sebagai bentuk gambaran diri yang tersusun atas identitas sosial dan identitas personal yang dalam permunculannya dapat bergantian ataupun bersamaan.

Konsep diri yaitu hubungan antara sikap dan keyakinan serta pandangan yang dimiliki oleh seseorang tentang karakteristik dan ciri-ciri sifat yang dimilikinya yang meliputi dimensi fisiknya, kelemahan yang dimilikinya, kepandaiannya, kegagalannya, motivasi yang dimiliki oleh dirinya, dan lain sebagainya yang merujuk pada harapanharapannya (Alwisol, 2007; Dayakisni \& Hudaniah, 2009).

Konsep diri yang sudah terbangun tentunya akan berubah, walaupun kemungkinannya akan sulit. Perubahan biasanya paling mudah terjadi ketika adanya penerimaan dari orang lain, yang membantu seseorang untuk mengurangi kecemasan dan ancaman serta mengakui dan menerima pengalaman-pengalaman yang sebelumnya ditolak (Feist \& Feist, 2010).

Faktor yang mempengaruhi konsep diri (Rakhmat, 2008), yaitu:1). Orang lain: jika kita diterima orang lain, dihormati dan 
disenangi karena keadaan diri kita, kita akan cenderung bersikap menghormati dan menerima diri kita. Sebaliknya bila orang lain meremehkan, menyalahkan dan menolak kita, kita cenderung tidak akan menyenangi diri kita sendiri.2). Kelompok rujukan: dalam pergaulan bermasyarakat kita pasti menjadi anggota berbagai kelompok. Ada kelompok yang secara emosional mengikat kita dan berpengaruh terhadap pembentukan konsep diri kita, ini disebut kelompok rujukan. Dengan melihat-lihat kelompok ini, orang mengarahkan perilakunya dan menyesuaikan dirinya dengan ciri-ciri kelompoknya.

Budaya tidak berakar pada biologi. Artinya, dua orang dari satu ras yang sama akan memiliki kesamaan nilai dan perilaku atau sangat berbeda dalam menampilkan nilai-nilai budaya mereka. Walaupun dua orang tersebut memiliki warisan rasial yang secara umum sama, akan tetapi proses enkulturasi dan sosialisasi kebudayaan yang mereka alami dapat mirip atau berbeda. Sehingga terlahir dalam ras tertentu tidak berarti mengadopsi budaya yang secara stereotipikal khas ras tersebut. Pemahaman yang sama terkait budaya juga menjelaskan bahwa kebangsaan seseorang tidak menjadi cerminan kebudayaannya (Matsumoto, 2008).

Definisi budaya dalam kaitannya dengan kajian perilaku harus menjelaskan dua hal. Pertama, keberadaan budaya merupakan faktor yang memberikan pengaruh eksternal terhadap individu. Kedua, keberadaan budaya dianggap sebagai bagian dari individu itu sendiri (Dayakisni \& Yuniardi, 2012).

Berdasarkan paparan tersebut, tujuan penelitian adalah mengetahui gambaran konsep diri mahasiswa fakultas psikologi Universitas Muhammadiyah Malang berdasarkan latar belakang budayanya. Beberapa manfaat yang dapat diperoleh dari penelitian ini, yaitu: memberikan gambaran konsep diri mahasiswa berdasarkan latar belakang budaya mereka; digunakan sebagai pedoman dalam pemetaan karakter mahasiswa; serta membantu mahasiswa mengenal diri mereka sendiri.

\section{METODE PENELITIAN}

Penelitian ini menggunakan pendekatan kuantitatif deskriptif untuk mengetahui kondisi yang sebenarnya berdasarkan jawaban subjek dan menyajikan data secara deskriptif berdasarkan temuan yang diperoleh di lapangan. Penggunaan metode deskriptif dalam penelitian ini bertujuan membuat deskripsi, gambaran yang sistematis, faktual dan akurat, mengenai fakta-fakta, sifat-sifat serta hubungan antar fenomena yang diteliti (Nazir, 2005).

Subjek dalam penelitian ini adalah 261 orang mahasiswa fakultas psikologi Universitas Muhammadiyah Malang. Metode yang digunakan dalam pengambilan sampel adalah accidental sampling. Artinya subjek dipilih berdasarkan aksesbilitas penelitian.

Konsep diri merupakan variabel yang akan dikaji dalam penelitian ini. Berdasarkan kajian pustaka diatas, konsep diri adalah suatu bentuk pemahaman tentang diri sendiri oleh seseorang berdasarkan lingkungan sosialnya. Instrumen yang digunakan dalam penelitian ini berupa pertanyaan terbuka yang dikembangkan sendiri oleh peneliti berdasarkan pada pemahaman konsep diri tersebut. Terdapat empat pertanyaan yang harus dijawab oleh subjek penelitian, yaitu: 1) bagaimana anda menggambarkan tentang diri anda sendiri? 2) bagaimana ayah anda menggambarkan tentang diri anda? 3) bagaimana ibu anda menggambarkan tentang diri anda? 4) bagaimana teman anda menggambarkan tentang diri anda?

Langkah penelitian diawali dengan menyiapkan instrumen berupa empat pertanyaan terbuka mengenai konsep diri. Selanjutnya, dilakukan penyebaran instrumen pada subjek penelitian yang dilakukan klasikal. Kemudian peneliti 
mengelompokkan jawaban subjek kedalam dua jenis konsep diri ,yaitu independen bilamana subjek menelaskan dirinya sebagai berorientasi pada mempengaruhi orang lain dalam bertindak, melakukan sesuatunya dengan mandiri, serta berpikir analitis. Dan interdependen bilamana subjek menyebutkan dirinya sebagai cenderung menyesuailan dengan orang lain dalam bertindak, melakukan sesuatu sesuai dengan aturan/norma sosial, dan berpikir holistik. Berikutnya, data yang telah dikoding dari penyebaran instrumen dianalisis menggunakan analisa kuantitatif deskriptif, tabulasi silang. Tabulasi silang dilakukan untuk mengetahui persentase dari kesimpulan jawaban-jawaban yang diperoleh.

\section{HASIL DAN PEMBAHASAN}

Penelitian ini mengambil subyek sebanyak 261 mahasiswa mahasiswa Fakultas Psikologi Universitas Muhammadiyah Malang. Berikut ini adalah gambaran data demografi dari subyek penelitian:

Tabel 1.

Deskripsi demografi

\begin{tabular}{|c|c|c|}
\hline Kategori & Frekuensi & Persentase \\
\hline \multicolumn{3}{|l|}{ Jenis Kelamin } \\
\hline Laki-laki & 93 & $35,6 \%$ \\
\hline Perempuan & 168 & $64,4 \%$ \\
\hline \multicolumn{3}{|l|}{ Usia } \\
\hline Remaja Akhir & 258 & $98,9 \%$ \\
\hline Dewasa Awal & 3 & $1,1 \%$ \\
\hline \multicolumn{3}{|l|}{ Suku } \\
\hline Jawa & 195 & $74,7 \%$ \\
\hline Non-Jawa & 66 & $25,3 \%$ \\
\hline \multicolumn{3}{|l|}{ AsalKepulauan } \\
\hline Jawa & 180 & $69 \%$ \\
\hline Kalimantan & 42 & $16,1 \%$ \\
\hline Nusa Tenggara & 13 & $5 \%$ \\
\hline Sulawesi & 11 & $4,1 \%$ \\
\hline Sumatera & 8 & $3 \%$ \\
\hline Kepulauan Riau & 2 & $0,8 \%$ \\
\hline Maluku & 1 & $0,4 \%$ \\
\hline Bali & 2 & $0,8 \%$ \\
\hline Papua & 2 & $0,8 \%$ \\
\hline
\end{tabular}

Berdasarkan tabel 1 diketahui distribusi demografi dari subjek penelitian. Subjek pada penelitian ini lebih banyak perempuan dengan persentase sebesar $64,4 \%$. Kelompok usia subjek sebagian besar adalah remaja akhir dengan rentang usia 17-22 tahun dan persentase 98,9\%.
Mayoritas yang menjadi subjek penelitian adalah suku Jawa $(74,7 \%)$. Ini sejalan dengan asal kepulauan dari subjek dengan persentase sebesar 69\%. Hal ini sangat mungkin terjadi, karena lokasi penelitian dilakukan di Kota Malang.

Tabel 2.

Deskripsi data 


\begin{tabular}{cll}
\hline Kategori & Frekuensi & Persentase \\
\hline $\begin{array}{c}\text { KonsepdirimenurutDirisendiri } \\
\text { Tidak Ada } \\
\text { Interdependen }\end{array}$ & 2 & $0.8 \%$ \\
Independen & 115 & $44 \%$ \\
Konsepdirimenurut Ayah & 144 & $55,2 \%$ \\
Tidak Ada & & \\
Interdependen & 7 & $2,7 \%$ \\
$\quad$ Independen & 138 & $52,9 \%$ \\
Konsepdirimenurutlbu & 116 & $44,4 \%$ \\
Tidak Ada & & \\
Interdependen & 2 & $0,8 \%$ \\
Independen & 151 & $57,8 \%$ \\
KonsepdirimenurutTeman & 108 & $41,4 \%$ \\
Tidak Ada & & \\
Interdependen & & $1,5 \%$ \\
Independen & 4 & $51,3 \%$ \\
\hline
\end{tabular}

Tabel 2 menunjukkan bahwa terdapat 4 kelompok konsep diri subjek, yaitu: menurut diri sendiri, ayah, ibu, dan teman. Pada setiap kelompok, subjek menggambarkan diri mereka menjadi diri interdependen dan diri independen. Namun, terdapat $0,8 \%$ pada konsep diri menurut diri sendiri dan ibu; $1,5 \%$ pada konsep diri menurut teman; serta 2,7\% pada konsep diri menurut ayah yang tidak dituliskan oleh subjek. Orang tua, baik ayah maupun ibu cenderung menilai konsep diri subjek dalam kategori interdependen dengan persentase ayah sebesar $52,9 \%$ dan persentase ibu sebesar $57,8 \%$. Sejalan dengan itu, teman juga menilai diri subjek sebagai individu yang cenderung interdependen dengan persentase sebesar $51,3 \%$. Hanya subjek sendiri yang menilai diri mereka sebagai individu yang independen dengan persentase sebesar $55,2 \%$.

Tabel 3.

Uji hubungan antar kelompok konsep diri

\begin{tabular}{lll}
\hline konsep diri menurut & $\mathbf{R}$ & $\mathbf{p}$ \\
\hline Diri sendiri*Ayah & 0,302 & 0,000 \\
Diri sendiri*lbu & 0,528 & 0,000 \\
Diri sendiri*Teman & 0,419 & 0,000 \\
Ayah*Ibu & 0,658 & 0,000 \\
Ayah*Teman & 0,389 & 0,000 \\
lbu*Teman $^{*}$ Teman & 0,406 & 0,000 \\
\hline
\end{tabular}

Pada tabel 3 berdasarkan uji korelasi phi dapat dilihat keterkaitan antar konsep diri subjek penelitian. Hasil menunjukkan bahwa antar kelompok penilai konsep diri memiliki keterkaitan karena nilai $\mathrm{p}<$
0,01. Diketahui juga bahwa konsep diri menurut diri sendiri dan ibu $(r=0,528)$; serta konsep diri menurut ayah dan ibu ( $r$ $=0,658$ ) memiliki keterkaitan yang kuat.

Tabel 4.

Uji hubungan antar konsep diri dan demografi 


\begin{tabular}{lll}
\hline Variabel & $\mathbf{r}$ & $\mathbf{P}$ \\
\hline Diri sendiri*Jenis Kelamin & 0,030 & 0,891 \\
Diri sendiri*Usia & 0,049 & 0,727 \\
Diri sendiriSuku & 0,050 & 0,721 \\
Diri sendiri*Asal Kepulauan & 0,186 & 0,911 \\
Ayah*Suku & 0,077 & 0,462 \\
Ayah*Asal Kepulauan & 0,193 & 0,880 \\
lbu*Suku & 0,154 & 0,045 \\
lbu*Asal Kepulauan & 0,179 & 0,939 \\
Teman*Suku & 0,055 & 0,671 \\
Teman*Asal Kepulauan & 0,189 & 0,901 \\
\hline
\end{tabular}

Keterkaitan konsep diri dan demografi dapat dilihat pada tabel 4 berdasarkan uji korelasi phi yang menunjukkan penilaian konsep diri menurut ibu memiliki keterkaitan yang lemah dengan demografi suku $(r=0,154$; $p<0,05)$.Selain itu, diketahui bahwa tidak ada keterkaitan antara penilaian konsep diri baik menurut diri sendiri, ayah, ibu, maupun teman terhadap demografi.

Berdasarkan hasil penelitian diketahui bahwa terdapat 4 kelompok konsep diri subjek, yaitu: menurut diri sendiri, ayah, ibu, dan teman. Pada setiap kelompok, subjek menggambarkan diri mereka menjadi diri interdependen dan diri independen. Penilaian konsep diri tidak jauh berbeda antara diri interdependen dan diri independen berdasarkan keempat kelompok tersebut. .Ayah, ibu dan teman cenderung menilai konsep diri subjek dalam kategori interdependen. Sedangkan subjek menilai konsep dirinya cenderung pada kategori independen.

Eliana (2003) menyebutkan bahwa konsep diri seseorang dipengaruhi oleh peran yang dimilikinya saat ini. Hal ini menjelaskanbagaimana subjek penelitian yang merupakan mahasiswa dan sebagian besar berasal dari luar malang menilai diri mereka cenderung independen. Sedangkan, ayah, ibu, dan teman menilai diri subjek cenderung interdependen. Diri independen, dijelaskan dengan karakter diri yang berorientasi pada mempengaruhi orang lain dalam bertindak, melakukan sesuatunya dengan mandiri, serta berpikir analitis. Sedangkan, diri interdependen merupakan kategori yang bertolak belakang dengan diri independen, yaitu: cenderung menyesuaikan dengan orang lain dalam bertindak, melakukan sesuatu sesuai dengan aturan/norma sosial, dan berpikir holistik (Kitayama, Duffy, \& Uchida, 2010). Penelitian lainnya menyebutkan bahwa konsep diri siswa dengan suku jawa memiliki hubungan positif dengan asertivitas mereka dalam berkomunikasi (Pratiwi, 2015).

Secara umum, dunia membagi dua kategori komunitas berdasarkan orientasi nilai budayanya, yakni individualis dan kolektivis (Hofstede, 1980). Negara barat memiliki konsep individualis yang berfokus pada kemandirian, sedangkan negara timur memiliki konsep kolektivis dengan arti saling bergantung/terikat (Markus \& Kitayama, 1991). Pembagian tersebut juga sama maknanya dengan diri interdependen yang berarti keterikatan dan diri independen berarti mandiri. Indonesia termasuk negara dibagian timur dengan budaya yang cenderung kolektivis. Kelompok kolektivis menggambarkan diri mereka berdasarkan konteks sosial mereka (Markus \& Kitayama, 1991). Dibandingkan dengan kelompok individualis, orang-orang dalam kelompok kolektivis memiliki perhatian lebih dalam terhadap nilai-nilai didalam keluarga mereka sebagai komponen yang membentuk konsep dirinya (Fuadhy \& Retnowati, 2013).

Dampak penilaian diri yang dilakukan baik oleh diri sendiri, ayah, ibu, 
maupun teman ialah terbentuknya konsep diri seseorang yang akan mempengaruhi beberapa aspek psikologi, seperti persepsi diri, penjelasan sosial, motivasi berprestasi, peningkatan diri, serta emosi seseorang (Dayakisni \& Yuniardi, 2012). Artinya seseorang dengan penilaian diri independen akan cenderung memiliki emosi independen. Sebaliknya, seseorang dengan penilaian diri interdependen akan cenderung memiliki emosi yang interdependen pula (Kitayama, Duffy, \& Uchida, 2010).

Hasil lainya menunjukkan keterkaitan antar konsep diri subjek penelitian dengan keterkaitan penilaian konsep diri menurut diri sendiri dan ibu; serta konsep diri menurut ayah dan ibu memiliki keterkaitan yang kuat. Akan tetapi, hanya penilaian konsep diri menurut ibu yang memiliki keterkaitan lemah dengan demografi suku. Pada analisa yang sama, tidak ada keterkaitan antara penilaian konsep diri baik menurut diri sendiri, ayah, ibu, maupun teman terhadap demografi. Ini tidak sejalan denganpenelitian sebelumnya yang menunjukkan perbedaan konsep diri yang dimiliki seseorang dengan latar belakang budaya yang berbeda (Watkins \& Andres, 1997; Eaton \& Louw, 2000; Tarakanita \& Widiarti, 2002; Yaman \& Mesman, 2010; Fuadhy \& Retnowati, 2013; Nurhadi, 2013). Penelitian ini sejalan dengan penelitian yang dilakukan oleh Fatimah (2013) yang menunjukkan bahwa konsep diri tidak memiliki kaitan dengan gaya hidup.Namun bertentangan dengan penelitian Setiawan (2013) yang menyebutkan bahwa mentoring agama akan meningkatkan konsep diri seseorang.

\section{SIMPULAN}

Hasil penelitian ini menunjukkan bahwa subjek menggambarkan diri mereka kedalam 4 kelompok, yaitu: menurut diri sendiri, ayah, ibu, dan teman. Setiap kelompok menggambarkan diri interdependen dan diri independen. Ayah, ibu dan teman cenderung menilai konsep diri subjek dalam kategori interdependen. Sedangkan subjek menilai konsep dirinya cenderung pada kategori independen. Hasil lainnya menunjukkan keempat kelompok penilaian konsep diri saling terkait. Akan tetapi, variabel demografi, seperti jenis kelamin, usia, suku, dan asal kepulauan tidak memiliki keterkaitan dengan konsep diri, kecuali penilaian konsep diri menurut ibu dan demografi suku yang memiliki keterkaitan.

Berdasarkan penelitian yang telah dilakukan dapat ditarik beberapa implikasi, baik untuk subjek penelitian maupun peneliti selanjutnya. Subjek penelitian yang berada pada usia remaja akhir dan dewasa awal perlu memerhatikan lingkungan sosial mereka agar tidak terpengaruh pada hal-hal yang kurang baik. Selain itu, subjek juga dapat lebih terbuka terhadap orang tua, mengingat keluarga merupakan lingkungan sosial pertama yang dimiliki oleh seseorang.

$\begin{array}{ccc}\text { Kepada } & \text { peneliti } & \text { selanjutnya } \\ \text { diharapkan } & \text { dapat } & \text { melakukan }\end{array}$
pengembangan dari penelitian ini dengan memperbanyak jumlah subjek penelitian dan meratakan distribusi suku serta asal kepulauan. Peneliti selanjutnya juga dapat melihat keterkaitan konsep diri dengan beberapa variabel yang memiliki pengaruh langsung, seperti: pengaruh kelompok, relasi interpersonal, kepribadian, serta pola asuh.

\section{DAFTAR PUSTAKA}

Afif, A. (2015). Teori identitas sosial. Yogyakarta: UII Press.

Alwisol. (2007). Psikologi kepribadian. Malang: UMM Press.

Boeree, G.C. (2013). Personality theories: Melacak kepribadian anda bersama psikolog dunia. Yogyakarta: Ar-Ruzz Media. 
Burns, R.B. (1993). Konsep diri, teori, pengukuran, perkembangan dan peilaku, Terjemahan. Jakarta: Arcan.

Dayakisni, T., \& Hudaniah. (2009). Psikologi sosial. Malang: UMM Press.

Dayakisni, T., \& Yuniardi, S. (2012). Psikologi lintas budaya. Malang: UMM Press.

Eaton, L. \& Louw, J. (2000). Culture and self in South Africa: Individualism-collectivism predictions. The Journal of Psychology, 140(2), 210-217.

Eliana, R. (2003). Konsep diri pensiunan. Sumatra Utara: USU digital library, 2, 158-162.

Fatimah, S. (2013). Pengaruh gaya hidup dan konsep diri terhadap pengambilan keputusan konsumen dalam memilih coffeshop di Samarinda. Skripsi, Fakultas Psikologi UNTAG, Samarinda.

Feist \& Feist. (2010). Teori kepribadian. Jakarta: Salemba Humanika.

Fuadhy, R.M. \& Retnowati, S. (2013). Javanesse adolescents self concept based on parents and second parents perceptions. Indigenous and Cultural Psychology Working Paper Series, 3, 1-22.

Fuhrmann, B.S. (1990). Adolescence, Adolescents. Illinois: Scott.

Hofstede, G. (1980). Culture's consequenses: International differencies in work-related values. Baverly Hills: Sage.

Kitayama, S., Duffy, S., \& Uchida, Y. (2010). Self as cultural mode of being. Dalam S. Kitayama\& D. Cohen (Eds), Handbook of cultural psychology (pp. 136-174). London: The Guilford Press.

Lowie, R.H. (1917). Culture and ethnology. New York: Douglas C. Mcmurtrie.

Markus, H \& Kitayama. (1991). Culture and the self: Implications for cognition, emotion and motivation. Psychological Review, 98(2), 224-253.

Matsumoto, D. (2008). Pengantar Psikologi Lintas Budaya. Yogyakarta: Pustaka Pelajar Offset.

Nazir, Moh. (2005). Metode penelitian. Bogor: Penerbit Ghalia Indonesia.

Nurhadi, R.A. (2013). Hubungan antara konsep diri dan penyesuaian diri pada remaja di Islamic Boarding School SMPIT Daarul Hikmah Bontang. Skripsi, Jurusan Psikologi Fakultas Psikologi UM, Indonesia.

Pratiwi, W. E. (2015). Pengaruh Budaya Jawa dan Harga Diri terhadap Asertivitas pada Remaja Siswa Kelas X di SMA Negeri 3 Ponorogo. Jurnal Psikologi, 3(1), 348-357.

Rakhmat, J. (2008). Psikologi komunikasi. Bandung: Penerbit Rosdakarya.

Santrock, J. W. (2010). Life-span Development 13th ed. New York: McGraw-Hill.

Schultz, D. (1991). Psikologi pertumbuhan: Model-model kepribadian sehat, Terjemahan. Yogyakarta: Kanisius.

Setiawan, I. (2013). Pengaruh Mentoring Agama Islam Terhadap Perubahan Konsep Diri Mahasiswa Muslim Universitas Sumatera Utara.

Sugiyono. (2007). Memahami Penelitian Kualitatif. Bandung: Alfabeta.

Tarakanita, I. \& Widiarti, P.W. (2002). Gambaran konsep diri mahasiswa kelompok etnis Sunda, kelompok etnis Cina dan kelompok etnis Jawa. Jurnal Psikologi, 10(2). 
Watkins, D. \& Andres, G. (1997).culture and spontaneous self concept among Filipino collage student. The Journal of Social Psychology, 137(4), 480-488.

Yaman, A.E. \& Mesman, J. (2010). Parenting in an individualistic culture with a colectivistic cultural background: The case of Turkish immigrant families with toddlers in the Netherlands. Journal Child Family Student, 19, 617-628. 